\title{
A resistência de Biridiya de Megiddo contra os ataques de Labayu de Siquém (EA 242-249, 365)*
}

\author{
The resistance of Biridiya from Megiddo against the \\ attacks of Labayu from Shechem (EA 242-249, 365)
}

\section{La resistencia de Biridiya de Megiddo contra los ataques de Labayu de Siquém (EA 242-249, 365)}

\author{
Élcio Valmiro Sales de Mendonça**
}

\begin{abstract}
RESUMO
Este artigo tem por objetivo analisar as cartas de El-Amarna referentes a Biridiya de Megiddo e seu conflito com Labayu de Siquém. O conteúdo de tais cartas fornece material importante para o conhecimento do ambiente político e da instabilidade do período final do domínio egípcio sobre as cidades-estados de Canaã. A análise será feita através da tradução das cartas (a partir de Moran e Rainey) e a partir do conteúdo de cada carta. O objetivo será também apresentar uma proposta de reconstrução cronológica das cartas originárias de Megiddo (Magidda).

Palavras-chave: Amarna; Biridiya; Megiddo; Akhenaten; Labayu.
\end{abstract}

\begin{abstract}
This article aims to analyze the letters of El-Amarna concerning Biridiya of Megiddo and his conflict with Labayu of Shechem. The contents of such letters provide important material for the knowledge of the political environment and the instability of the final period of the Egyptian rule over the city-states of Canaan. The analysis will be done by translating the letters (from Moran and Rainey) and from the contents of each letter. The objective will also be to present a proposal for chronological reconstruction of the letters originating from Megiddo (Magidda).

Keywords: Amarna; Biridiya; Megiddo; Akhenaten; Labayu.

\section{RESUMEN}

Este artículo tiene por objetivo analizar las cartas de El-Amarna referentes a Biridiya de Megiddo y su conflicto con Labayu de Siquém. El contenido de tales cartas presenta material importante para el conocimiento del ambiente político y la inestabilidad del período final del dominio egipcio sobre las ciudades-estados de Canaán. El análisis se realizará a través de la traducción de las cartas (a partir de Moran y Rainey) ya partir del contenido de cada carta. El objetivo será también presentar una propuesta de reconstrucción cronológica de las cartas originarias de Megiddo (Magidda).

Palabras Clave: Amarna; Biridiya; Megiddo; Akhenaten; Labayu.
\end{abstract}

\footnotetext{
* Este artigo é parte da produção de pesquisa realizada durante o ano de 2017 pelo Grupo de Pesquisa "Arqueologia do Antigo Oriente Próximo", da Universidade Metodista de São Paulo - Reg. no CNPq $\mathrm{N}^{\circ} 4338921870858325$.

** Doutor em Ciências da Religião (UMESP). Professor de Antigo Testamento na Universidade Metropolitana de Santos, UNIMES. Contato: elcio.mendonca@hotmail.com.br.
} 


\section{Introdução}

As cartas de Biridiya de Magidda (EA 242-249, 365) apresentam um conflito entre Biridiya (coalisão pró-Egito) e a coalisão anti-Egito liderada por Labayu, governador da cidade-estado de Siquém, e levada adiante por seus filhos, em 1350-1320 a.C. (NA'AMAN, 1992, p.174). Estas cartas de Biridiya de Magidda fazem parte de um grupo maior de cartas trocadas entre os governadores das cidades-estado de Canaã e o faraó Amenhotep III ou Amenhotep IV (Também conhecido como Akhenaten ou Akhenaton).

Este grupo de cartas não possui datação, segundo Mynarová (2011, p.123), somente quatro cartas possuem datações concretas ( $E A$ 11, EA 23, EA $27 \mathrm{e}$ EA 254). Entretanto, é possível que o conjunto de cartas de Biridiya de Magidda seja do período entre Amenhotep III e Amenhotep IV, por causa das citações ao sol nas saudações de quase todas as cartas, como na frase: "Fala ao rei, meu senhor e meu deus sol", que aparece nas cartas E $A$ 242, E $A$ 243, EA 244, EA 246, EA 247, EA 248, EA 249 e EA 365). Também por causa do momento de instabilidade e das revoltas contra o domínio egípcio sobre as cidades-estado de Canaã, que podem ser claramente apresentados na coalisão anti-Egito liderada por Labayu, governador de Siquém (FINKELSTEIN; NA'AMAN 2006, p.174-177 e GOREN; FINKELSTEIN; NA'AMAN, 2002), entre: Milkilu de Gezer ( $E A$ 250, EA 53-56, EA 289, EA 287), Ginti-Kirmil de Tagi, família de Milkilu (EA 249, EA 263, EA 289), Ba'lu-Meher de Tel Yoqneam ( $E A$ 245), Anaharath de Bayadi e Baduzana (EA 237-238); Pihilu, de Mut-Ba'lu, filho de Labayu, (EA 255, EA 250); Ashtaroth (EA 256, EA 364) e Shimon (EA 263) (FINKELSTEIN; NA'AMAN, 2006, p.177-179). Em contrapartida, uma coalisão liderada por Biridiya contra a coalisão liderada por Labayu foi formada: Biridiya de Megiddo (EA 244-246), Rohob (EA 249-250), Acsaf e Aco (EA 366; 245), Gath (EA 280) e Hazor (EA 364).

O destinatário das cartas de Biridiya é o rei do Egito, o faraó, embora não apareça seu nome em nenhuma das seis cartas. Porém, as indicações ao "rei" e ao "sol" e o discurso de submissão nos cabeçalhos das cartas mostram que foram enviadas para o faraó, rei do Egito. O nome de Biridiya aparece como remetente em seis cartas ( $E A$ 242, EA 243, EA 244, EA 246, EA 247 e $E A 365)$. A carta $E A 245$ não apresenta diretamente Biridiya como remetente, embora, pelo conteúdo, possivelmente seja ele, porque o autor diz que estava com Yashdata, o remetente da carta $E A$ 248. Nesta carta, Yashtada aparece como um aliado de Biridiya (EA 245, EA 248) (GOREN, FINKELSTEIN, NA'AMAN, 2004, p. 270-279).

Labayu é o assunto central de quase todas as cartas de Biridiya ( $E A$ 244-240). A EA 243 não menciona o nome Labayu, mas cita os 'Apirus. É 
possível que estes estivessem a serviço de Labayu no seu intento de conquistar Magidda (Megiddo).

\section{Megiddo (Magidda) na Idade do Bronze Tardio}

O sítio arqueológico de Tel Megiddo (em árabe: Tell Muteselim) tem uma longa história de ocupação. No total, somam-se em torno de seis mil anos. Desde o período do Bronze Antigo (3500-3000 aEC) e, talvez, anterior a isso. Sua importância estava na localização estratégica no que se refere ao controle da rota Caminho do Mar ou Via Maris, como passou a ser chamada no período romano (GOREN, FINKELSTEIN, NA'AMAN, 2004, p. 243).

Megiddo também era importante para controlar e proteger o grande vale fértil de Jezreel, que na área de Megiddo se chamava "Vale de Megiddo". Megiddo possui vinte estratos de ocupação, sendo os mais antigos (XIX e XX) os anteriores a 3500 a.C. (período Calcolítico). Os estratos XVI-XVIII são do Bronze Antigo (1950-3000 a.C.), os estratos XIII-XV são do Bronze Médio (1550-1950 a.C.), os estrados IX-XII são do Bronze Tardio (1350-1550 a.C.) (SHIPTON, 1939, p. 4).

As escavações em Tel Megiddo tiveram início com Gottlieb Schumacher (1903-1935), chegando a escavar até o período do Bronze Tardio, em torno do estrato XII e XIII ${ }^{1}$. Schumacher chegou a escavar o palácio do período canaanita localizado à direita do portão da cidadela do mesmo período. Não se sabe exatamente de quem era esse palácio, ou onde era o palácio de Biridiya em Megiddo, mas há evidências de um palácio na Megiddo do Bronze Tardio.

As cartas de Biridiya não foram encontradas em Megiddo, mas em El-Amarna, no Alto Egito, no final do século 19, entre 1887 e 1892. As tabuletas (cartas) foram encontradas por William Flinders Petrie durante as escavações em El-Amarna, entre os anos de 1891 e 1892². Flinders Petrie encontrou cerca de 350 tabuletas de argila com escrita cuneiforme, que eram as cartas trocadas entre os governantes de Canaã e o faraó (PETRIE, 1894, p. 1-8).

\section{As Cartas entre Biridiya e o faraó Amenhotep II (EA 242-249, 365)}

As cartas de Biridiya de Magidda formam um conjunto de oito cartas ( $E A$ 242, EA 243, EA 244, EA 245, EA 246, EA 247, EA 248 e EA 365) que foram enviadas de Magidda para faraó, possivelmente Amenhotep III, Akhenaten. Através do conteúdo destas cartas, é possível reconstruir, ainda que parcialmente, o ambiente político daquela época. O momento era de instabilidade entre as cidades-estados canaanitas dominadas pelo Egito, e re-

\footnotetext{
Confira https://www.pef.org.uk/profiles/gottlieb-schumacher. Acesso em 18 jun 2018.

2 Confira https://www.pef.org.uk/profiles/sir-william-flinders-petrie-1853-1942. Acesso em 18 jun 2018.
} 
voltas passaram a acontecer. Labayu, governador de Siquém, fez uma coalisão com outras cidades-estados canaanitas contra o domínio egípcio e começou a conquistar as cidades-estados contrárias a esta coalisão.

Labayu começa a conquistar e a dominar um território cada vez maior, e passa a avançar rumo ao vale de Jezreel e Megiddo, cujo objetivo parecia ser dominar o fértil vale e, talvez, conquistar a Galileia e a Alta Galileia, com importantes cidades-estados, como Hazor.

Labayu é preso quando começa a conquista de Megiddo, e é levado para o porto, a fim de embarcar como prisioneiro rumo ao Egito. Surata foi o encarregado de escoltar Labayu para o navio, mas, mediante pagamento de resgate, Surata deixa Labayu ir embora. Porém, Labayu é morto logo em seguida. Depois da morte de Labayu, seus filhos assumem o poder em Siquém e continuam a política de conquista de território do pai. Desta forma, o ambiente político instável é retratado nestas cartas, cuja duração deve ter sido em torno de quinze ou vinte anos.

As cartas possuem uma estrutura quase padrão: há um cabeçalho longo (em torno de quatro a oito linhas) e o conteúdo. Esta estrutura básica se repete em praticamente todas as cartas de El-Amarna, inclusive no conjunto das cartas de Megiddo.

A análise petrográfica das cartas de Megiddo concluíram que as tabuletas foram preparadas com materiais tipicamente locais. Em todas elas, o escriba retirou o material da região do vale de Megiddo para preparar as tabuletas para a escrita das cartas. Megiddo era uma cidade rica, sua localização nas proximidades da importante estrada internacional que ligava o Egito à Síria, seu vale fértil e suas amplas fontes de água garantiram sua posição de liderança e importância entre todas as demais cidades-estados do norte de Canaã (GOREN, FINKELSTEIN, NA'AMAN, 2004, p. 246).

\section{EA 242 - Os cidadãos estão em paz, mas eu estou em guerra}

(1-8) Fala ao rei, meu senhor e meu deus sol, a mensagem de Biridiya, o governante de Megiddo, seu servo leal: Aos pés do rei, meu senhor e meu deus sol, eu tenho me prostrado. (9-13) Eis que tenho atendido o pedido do rei, meu [senhor]: 30 bois, [XX ovelhas e cabras, $\mathrm{XX}$ av]es [....].

(14-17) [...Obser]vem, [todos os cida]dãos estão em paz, mas estou em guerra.

Esta carta fala do envio de mercadorias e animais para o Egito: bois, ovelhas, cabras, aves etc. Estas mercadorias foram enviadas para o faraó, vindas de Magidda. A tabuleta está danificada, portanto, não é possível saber o conteúdo completo da carta e se havia outras mercadorias. Nas linhas 14-17, Biridiya informa ao faraó que os cidadãos de Magidda estão em paz, 
porém ele estava em guerra. Possivelmente, informando o clima instável que já se instaurara na região por conta da revolta de Labayu (FINKELSTEIN; NA'AMAN, 2006, p. 177-179).

\section{EA 243 - Vigilância dia e noite}

(1-7) Fala ao rei, [meu] se[nhor] e meu deus sol, e [minha] d[ivindade], a mensagem de Biridi[ya], o fiel servo d[o rei]: Aos pés do rei, [meu] se[nhor] e meu deus sol e minha divindade, sete vezes e sete vezes eu tenho caído.

(8-18) Ouvi as palavras do rei, meu senhor e meu deus sol. E agora estou guardando a cidade de Megiddo, a cidade do rei, meu senhor, dia e noite. Durante o dia eu guardo os campos abertos com bigas e à noite, eu estou guardando os muros da [cidade d]o rei meu senhor. (19-22) Mas agora a hostilidade dos homens 'apiru está in[tensa] na terra, assim também o rei, meu senhor, seja informado com relação à sua terra.

Nesta carta, Biridiya amplia a saudação e enfatiza sua submissão ao faraó, chamando-o de "minha divindade". Também ele inclui na saudação a fórmula: "Aos pés do rei, meu senhor e meu deus sol e minha divindade, sete vezes e sete vezes eu tenho caído" (linhas 1-7). Esta frase também aparece, com algumas variações, nas cartas EA 244, EA 246, EA 247, EA 248 e $E A 365$.

Nas linhas 8-18, parece que o faraó já sabia dos conflitos que estavam acontecendo em Magidda e deu algumas orientações a Biridiya. Esta carta é uma resposta a uma outra carta, enviada por faraó para Biridiya, e ele informa que ouviu as palavras do faraó e por conta disso estava vigiando a cidade dia e noite. O governador de Magidda afirma que a cidade é do faraó "a cidade do rei, meu senhor". Durante o dia, ele envia guarnições para vigiarem os campos abertos e à noite a vigilância se restringe aos muros da cidade.

Biridiya informa ao faraó que um grupo conhecido como 'Apiru estava agindo com hostilidade contra ele. A expressão, traduzida aqui como "mas agora a hostilidade", mostra que este grupo não estava guerreando contra Magidda desde o início, mas que, no momento da escrita da carta EA 243, a hostilidade dos "Apirus tinha se tornado intensa. A carta termina com a frase "o rei, meu senhor, seja informado com relação à sua terra", mostrando que a terra pertencia ou estava sob o domínio do Egito.

\section{EA 244 - Labayu cerca Megiddo}

(1-8) Fala ao rei, meu senhor e meu deus sol. Assim diz Biridiya, o servo leal do rei: aos dois pés do rei, meu senhor e meu deus sol, sete vezes e sete vezes eu (tenho) caído.

(8-20) Que o rei, meu senhor, seja informado de que, desde que o exército regular regressou (ao Egito), Lab'ayu tem feito guerra contra mim, de modo que somos incapazes de tosquear as ovelhas ou de terminar a colheita. Nós não podemos mesmo sair pela porta da cidade por causa de Lab'ayu desde que ele descobriu que as tropas regulares não estão vindo. 
(21-29) E ago[ra], ele está determinado a tomar Megiddo. Que possa o rei, por favor, resgatar a sua cidade; não deixe Lab’ayu agarrá-la!

(30-38) Já que a cidade está arruinada por uma epidemia e pela pestilência(?). Assim pode o rei nos conceda cem soldados da guarnição para guardar sua cidade; Não deixe Lab’ayu agarrá-la!

(38-43) Como Lab’ayu não tem outra intenção. Ele procura a destruição de Megiddo.

Após a saudação padrão nas linhas 1-8, começa o conteúdo da correspondência. Esta carta apresenta o cerco feito por Labayu em Magidda. Biridiya manda um relatório sobre a situação da cidade agora cercada por Labayu de Siquém. Nas linhas 8-20, ele diz que desde que a guarnição egípcia retornou ao Egito, Labayu passou a guerrear contra Magidda, de forma que mudou a vida cotidiana da cidade. Ele informa que não conseguem mais tosquiar as ovelhas e nem conseguem concluir a colheita. Isto era um grande problema para uma cidade sitiada.

Biridiya informa que as pessoas não conseguem sair nem entrar na cidade pela porta, porque Labayu estava impedindo. Ele diz que desde que Labayu ficou sabendo que as tropas egípcias tinham se retirado, e que não havia nenhuma tropa chegando, aproveitara para cercar a cidade e investir contra ela.

Nas linhas 21-29, Biridiya suplica ao faraó que envie tropas para ajudá-lo a resistir aos ataques de Labayu. Ele repete duas vezes uma frase que demonstra bem o desespero dele: "Não deixe Lab’ayu agarrá-la!", ou "não deixa Lab’ayu conquistá-la!”. A carta termina nas linhas 30-43, nas quais o governador diz para o faraó que a cidade está arruinada por epidemia e pestilência, isto devido ao longo cerco. E finaliza pedindo o envio de guarnições egípcias, porque Labayu não quer outra coisa senão destruir Magidda.

\section{EA 245 - Labayu é capturado, mas Surata o liberta}

(1-14) Além disso, exortei os meus companheiros: "Se a divindade do rei, nosso senhor, permitir capturar Lab’ayu, então devemos trazê-lo vivo ao rei, nosso senhor". Mas minha égua foi ferida e eu me levantei depois disso e montei com Yashdata, mas quando cheguei, eles o tinham ferido.

(15-23) E eis que Yashdata é teu servo e ele entrou comigo na peleja, assim também a vida do re[i, me]u [senhor] seja concedida (a ele), e possa ele (Yashdata), ser visto [be]m [na presença] do rei, [meu] senhor [...].

(24-35) Mas Surata pegou La[b’ayu] desde a cidade de Megiddo e ele me disse: "Num navio eu vou mandá-lo para o rei”. Então Surata o pegou, mas ele o liberou para sua casa da cidade de Hannathon, e Surata pegou seu dinheiro do resgate de sua mão.

(36-40) Além disso, o que eu fiz ao rei, meu senhor, ele que me deprecia e honra meus associados mais jovens?

(41-47) Mas Surata libertou Lab'ayu e Surata libertou Ba'lu-Meher para sua casa(s). Assim o rei, meu senhor, seja informado. 
Esta carta está sem o tradicional cabeçalho. Talvez por causa do caráter de urgência demonstrado pelo conteúdo da carta, já que Labayu havia entrado em Magidda. Não aparece Biridiya como remetente da carta, mas o contexto indica que seja ele. Aparece aqui o nome de Yashdata, um aliado de Biridiya que luta ao lado dele na guerra contra a coalisão liderada por Labayu, cujo nome é mencionado cinco vezes em toda a carta.

Labayu está encurralado em Megiddo e é capturado por Surata dentro de Megiddo, e uma diligência é formada para levá-lo para o porto, pois um navio com destino ao Egito o espera. Biridiya pede ao rei, logo no início da carta, que lhe dê a oportunidade de capturar Labayu vivo, para que possa ser levado e julgado pelo próprio faraó no Egito. A carta E $A 244$ possivelmente tenha sido escrita antes da $E A 243$, pois o Egito não teria retirado a guarnição do exército, se soubesse do conteúdo da carta $E A$ 243. Megiddo cai, mas depois o Egito a retoma. Porém, logo após surgem os problemas de Jerusalém.

Biridiya relata um sério problema no final da carta, ele menciona que Surata, o encarregado pela escolta de Labayu, recebeu um pagamento para libertar Labayu e Ba'lu-Meher, antes de ser entregue no navio rumo ao Egito, e Labayu foge. A carta diz que Surata o libertou para a cidade de Hannathon após pegar o dinheiro do resgate. Labayu luta junto com Milki-illu, porém, Labayu não foi morto, então, Milki-illu faz aliança com os filhos de Labayu.

\section{EA 246 - Os filhos do Labayu continuam a hostilidade}

(1-7) Fa[la ao re]i, [meu] Senh[or e] meu deus sol, a mensagem de Biridiya, seu servo fiel. Aos pés do rei, me[u] senhor, e meu deus sol, sete vezes e sete vezes eu caí.

(8-9) Ouvi a mensagem que o rei $[\ldots . . .$.

Rev.

(1-11) E ho[stilidades ...] e agora [......] vo[cê] é [....]. Pode o rei, meu Deus, ser informado. E agora os dois filhos de Lab'ayu estão dando a sua prata aos homens de 'apîru e aos homens da terra do S[utû,] faze[r guerra] contra mim. Assim pode o re]i ser informado] a respeito de [sua terra.]

Esta carta foi escrita após a morte de Labayu. Não passou muito tempo e o governo dos seus filhos continuou a mesma política expansionista do pai e a guerra contra Megiddo. A hostilidade continua. Boa parte do conteúdo da carta está perdida, devido aos danos no tablete, mas uma pequena parte pode ser traduzida e traz informações preciosas a respeito das investidas contra Megiddo.

O que sobrou da carta diz que os filhos de Labayu contrataram os 'Apirus da terra de Sutû para guerrearem contra Biridiya. Um bando de soldados mercenários pagos para fazerem o trabalho sujo que os filhos de Labayu não 
queriam fazer com suas próprias mãos, pelo menos é o que indica o teor da carta. A carta não informa em que circunstâncias Labayu fora morto, só diz que os filhos dele continuaram o projeto do pai. Segundo a carta EA 250, a coalisão, após a morte de Labayu, teria passado pelas mãos de Gina, atual cidade palestina de Jenin (a bíblica Beth-Hagan, conforme 2Rs 9.27). Logo após Gina ter tomado a frente da coalisão, os filhos de Labayu assumiram e levaram a diante a coalisão.

\section{EA 247 - Quem sou eu, um cão?}

(1-7) [Fala ao rei, meu senhor e meu deus do sol; Assim diz Biridiyu, seu servo fiel. Aos pés do rei, meu senhor, e meu deus do sol, sete vezes e sete vezes eu caí.

(8-13) Com relação à mensagem do rei, meu senhor, que escrevestes a mim ao rei, meu senhor, eu tenho ouvido [o rei] com muito cuidado.

(14-18) E quem [sou eu], [um cão], se [eu] não [ouvir o pedido

do rei, meu senhor?]

(18-22) [Agora eu estou me preparando]

Esta carta possui o mesmo cabeçalho que as demais cartas. Seu conteúdo é curto e incompleto. Biridiya menciona uma carta enviada pelo rei para ele, porém não se sabe o conteúdo dela, porém, ele reafirma sua submissão ao faraó, expressando-se com a frase de intensidade traduzida como: "com muito cuidado".

Não se sabe qual foi o pedido do rei na carta, entretanto, nas linhas 14-18, o autor da carta faz uma pergunta retórica: "E quem sou eu, um cão, se eu não ouvir o pedido do rei, meu senhor?”. Aqui, possivelmente, ele está reafirmando sua submissão e sua posição pró-Egito, quando diz que ele mesmo seria um cão se não ouvisse o pedido do rei.

A carta termina com uma frase que está danificada "agora, eu estou me preparando [...]", dando a ideia de que ele estava se preparando para algo, ou para a guerra ou para atender ao pedido do rei. É possível que se refira ao pedido do rei, já que nesta carta ele não menciona os conflitos. O problema é que a carta está incompleta e não fornece informações suficientes para determinar com mais exatidão.

\section{EA 248 - Yashdata se refugia com Biridiya de Megiddo}

(1-8) Fala ao rei, meu senhor, e ao meu deus-sol e à minha divindade; A mensagem de Yashdata, o servo leal do rei e a sujeira sob os pés do rei: Aos pés do rei, meu senhor, e meu deus do sol e minha divindade, sete vezes e sete vezes eu caí.

(9-17) Que o rei, meu senhor, seja informado de que todos os bens que o rei, meu senhor, havia dado a um servo, foram expropriados; Os homens da cidade de Taanach abateram meu gado e me expulsaram.

(18-22) E agora estou com Biridiyu. Assim o rei, meu senhor, seja informado sobre seu servo 
O remetente desta carta é Yashdata, aliado de Biridiya. Ela tem o mesmo cabeçalho das demais correspondências e possui oito linhas. O conteúdo da carta mostra que Magidda havia sido invadida e saqueada. Yashdata informa ao rei que todos os bens que ele havia dado ao "seu servo", Biridiya, tinham sido levados embora. Outra informação importante é que foram os homens de Tanaach que saquearam e abateram o gado e o expulsaram da cidade.

Esta carta parece ter sido escrita antes da carta $E A 245$, porque ela dá informações mais detalhadas a respeito da invasão de Labayu e dos homens que fizeram parte de sua coalisão, no caso, os homens de Tanaach. Interessante que os homens de Tanaach não aparecem inicialmente como parte da coalisão encabeçada por Labayu, nem naquela encabeçada por Biridiya, entretanto, eles aparecem nesta carta de Yashdata como um dos aliados de Labayu.

A situação estava se agravando durante o conflito, pois o gado havia sido abatido e as plantações (cf. EA 244) foram devastadas e roubadas. Segundo Finkelstein, Goren e Na'aman (2004, p.246), Yashdata era o governador de Taanach, que fora expulso por uma revolta na cidade, na qual os homens da cidade tomaram seus bens e o expulsaram da cidade. Dentro do conflito da coalisão de Labayu, Yashdata se vê obrigado a se refugiar com Biridiya em Megiddo.

Outra hipótese é que, com a guerra em avançando, Biridiya se vê obrigado a sair da cidade e a se refugiar com seu aliado Yashdata. O próprio Yashdata informa ao rei que Biridiya estava com ele e que era para o rei estar ciente disso. Por este motivo, a carta EA 248 deve ter sido escrita antes de $E A$ 244, porque o conflito estava em pleno desenvolvimento e a cidade estava sendo tomada. $\mathrm{Na} E A$ 244, o conflito já havia sido encerrado e Labayu preso por Surata. Entretanto, a primeira hipótese parece ser a mais plausível.

\section{EA 365 - Relatório de Biridiya sobre Shuném ao faraó}

(1-7) Fala [ao rei], meu senhor, e meu [sol]; A mensagem de Biridiya, o fiel servo do rei: Aos pés do rei, meu senhor, sete vezes e sete vezes eu caí.

(8-9) Que o rei, meu senhor, seja informado acerca do seu servo e sobre a sua cidade.

(10-14) Agora, sou eu quem estou cultivando na cidade de Shuném e sou eu quem está trazendo a corveia.

(15-29) Olha, os governantes da cidade que estão comigo não estão fazendo como eu estou fazendo; Eles não estão cultivando na cidade de Shuném e eles não estão trazendo corveia trabalhadores. Mas eu, por mim, estou trazendo uma corveia trabalhadores. De Yapo (yafo, Jope) eles vêm, daqueles que estão sob a minha autoridade aqui e da terra de Nuribda.

(30-31) Portanto, o senhor, meu senhor, fique atento a respeito da sua cidade.

Esta carta possivelmente seja a primeira a ser enviada para o Egito, porque a situação ainda estava tranquila de certa forma. Ela deve ter sido 
escrita antes da chegada dos 'Apirus e de Labayu. Aqui, Biridiya está dando um relatório para o rei, o faraó, sobre a cidade que estava sob sua responsabilidade, Shuném (a bíblica Suném; em árabe, Sulam), a 14 km a nordeste de Megiddo, próximo da atual cidade de Afula.

Segundo a carta, Biridiya tinha trazido trabalhadores em sistema de corveia de Yapo (Yafo, Jope) e da terra de Nuribda para Shuném. Nas linhas 15-29, ele diz que havia governantes da cidade com ele e que estes estavam fazendo conforme ele fazia. Primordialmente, parece que tais trabalhadores estavam encarregados de realizar trabalhos agrícolas no cultivo da terra. Isto porque Shuném está no lado norte do fértil vale de Jezreel e é possível ver a cidade do alto da colina de Megiddo, antiga Magidda ou Magidda.

A correspondência possui um teor de tranquilidade, ainda não havia a tensão dos conflitos contra Labayu e sua coalisão, nem contra os homens de Taanach. Esta deve ter sido, de fato, a primeira carta do conjunto de cartas de Biridiya, porque após essa carta a situação em Canaã só piora. Ela deve ter sido enviada no início do reinado de Amenhotep III, antes das ameaças e do conflito com Labayu.

\section{Proposta para uma cronologia das cartas de Megiddo}

As cartas de Amarna não estão agrupadas em ordem cronológica, mas, conforme as análises deste artigo, podemos chegar a uma proposta para a organização das mesmas. Isto não quer dizer que a proposta seja exata, mas é possível, levando em conta a temática e conteúdo de cada carta. Dispondo as cartas de Megiddo numa ordem cronológica, teríamos a seguinte proposta, da mais antiga para a mais recente:
1) EA 365 - Relatório de Biridiya sobre Shuném ao faraó
2) $E A 242$ - Os cidadãos estão em paz, mas eu estou em guerra
3) EA 243 - Vigilância constante: dia e noite
4) $E A 244$ - Labayu cerca Megiddo
5) EA 248 - Yashdata se refugia com Biridiya de Megiddo
6) EA 245 - Labayu é capturado, mas Surata o liberta
7) EA 246 - Os filhos do Labayu continuam a hostilidade
8) EA 247 - Quem sou eu, um cão? (carta danificada)

Esta sequência de cartas parece fazer sentido, e ajuda a compreender o ambiente hostil após as iniciativas de Labayu contra Megiddo. São oito cartas que iniciam com a $E A$ 365, que apresenta um momento tranquilo na vida da cidade e das cidades que estavam sob o domínio de Biridiya de Megiddo. Porém, a carta EA 242 e EA 243 descrevem os momentos iniciais do conflito, quando o governador de Megiddo estava se sentindo pressionado pelas ameaças e a vigilância constante de Megiddo. A carta EA 244 apresenta o 
cenário do conflito, quando Labayu cerca a cidade, e a carta E $A 248$ descreve a tomada de Taanach das mãos de Yashdata e o refúgio dele com Biridiya de Megiddo, quando guerreiam juntos.

Na carta EA 245, Labayu é capturado por Surata e levado para um navio que o esperava para ser levado para o Egito, a fim de que se apresentasse diante do rei, faraó, e fosse possivelmente julgado ou morto. Entretanto, esta mesma carta informa que Surata recebeu um pagamento e libertou Labayu, que se refugiou na cidade de Hannathon.

A carta EA 246 informa que Labayu estava morto e que seus filhos deram continuidade ao projeto do pai, e encabeçaram a coalisão após Gina (Jenin), e continuaram com a hostilidade contra Megiddo. A revolta de Labayu e de seus filhos pode ser vista no conjunto de cartas de Labayu de Siquém (EA 252-250). A última carta, EA 247, está danificada e não é possível saber todo o seu conteúdo, porém, Biridiya se compara a um cão, caso não ouvisse as palavras do rei. Esta carta também diz que ele estava se preparando para algo, entretanto, não é possível saber com qual objetivo, por isso esta carta foi posta por último, talvez porque Biridiya estivesse se preparando para retomar a cidade, mas isso é só uma conjectura.

\section{Considerações Finais}

As cartas de El-Amarna fornecem informações importantíssimas sobre a situação de Canaã no período final do Bronze Tardio. Ela mostra como foi a presença do Egito nesta região e como era a diplomacia entre os governantes das cidades-estados canaanitas. Também fornecem material suficiente para conhecer os conflitos que culminaram com o recuo do Egito e o fim do seu domínio em Canaã.

Particularmente, o conjunto de cartas de Biridiya, governador de $\mathrm{Me}$ giddo (Magidda), nos dá a conhecer como era dominada aquela região e como o governante se relacionava com o faraó egípcio. Os cabeçalhos das cartas informam grande submissão, e o Egito dava certa liberdade, desde que cumprissem com seus compromissos.

O domínio egípcio em Canaã no final do Bronze Tardio pode ser visto nos relatórios das escavações em Tel Megiddo, onde diversos artefatos egípcios foram encontrados, inclusive uma tumba egípcia foi encontrada na última temporada de escavações em Tel Megiddo ${ }^{3}$, através do projeto Megiddo Expedition 2016 ${ }^{4}$. Conhecer os conflitos existentes entre o governador de Siquém e o de Megiddo é surpreendente, bem como o intento do governador

3 Veja https://www.nationalgeographicbrasil.com/historia/2018/03/exclusivo-tumba-real-em-canaa-joga-luz-sobre-antiga-cidade-biblica. Acesso em 18 jun 2018.

$4 \quad$ Veja https://sites.google.com/site/megiddoexpedition/. Acesso em 18 jun 2018. 
de Siquém em dominar o território e as cidades-estados ocupadas pelo Egito. Conhecer o conteúdo destas cartas é importante para reinterpretarmos a história bíblica antes do período do Ferro I e II, e reescrevermos as antigas histórias das origens de Israel, bem como, do surgimento das monarquias em fins do século 10 a.C. e da formação do Estado Israelita, em meados do século 9 a.C.

\section{Referências Bibliográficas}

GOREN, Y.; FINKELSTEIN, I.; NA'AMAN, N. (eds.). Inscribed in clay: provenance study of the Amarna letters and other ancient Near Eastern texts. Tel Aviv University: Tel Aviv, 2004

GOREN, Y.; FINKELSTEIN, I.; NA'AMAN, N. The seat of three disputed canaanite rulers according to petrographic investigation of the Amarna tablets. In: Tel Aviv 29, 2002, p. 221-237

FINKELSTEIN, Israel. O reino esquecido: arqueologia e história de Israel Norte. [Trad. Silas Klein Cardoso \& Élcio Valmiro Sales de Mendonça]. São Paulo: Paulus, 2015.

FINKELSTEIN, Israel. The last labayu: king Saul and the expansion of the first north israelite territorial entity. In: AMIT, Y.; BEN ZVI, E.; FINKELSTEIN, I; LIPSCHITS, O. (eds.). Essays on ancient Israel in its Near Eastern context. A tribute to Nadav Na'aman. Winona Lake: Einsenbrauns, 2006, p. 171-187.

FINKELSTEIN, Israel; NA'AMAN, Nadav. Shechem of the Amarna Period and the rise of the northern kingdom of Israel. In: CZERNY, E. et alii (eds.). Timelines: studies in honor of Manfred Bietak. Vienna: Peeters, 2006, pp. 349-356.

MORAN, W. L. The Amarna letters. Baltimore: Johns Hopkins, 1992

MYNÁROVÁ, J. Amarna Letters. In: BAGNALL, R; BRODERSEN, K.; CHAMPION, C. ERSKINE, A.; HUEBNER, S. (eds.). The Encyclopedia of Ancient History. vol. 1, Malden, Oxford, Carlton: Wiley-Blackwell, 2013, v.1, p. 347-348

MYNÁROVÁ, J. Language of Amarna - Language of diplomacy: perspectives on the Amarna Letters. Praga: Czech Institute of Egyptology, 2007.

NA'AMAN, Nadav. Amarna Letters. In: ABD. New York: Doubleday, 1992, v.1, p. 174.

PETRIE, W. M. Flinders. Tell el Amarna. California: Methuen \& Co, 1894.

RAINEY, A. (aut.); SCHNIEDEWIND, W.; COCHAVI-RAINEY, Z. (eds.). The El-Amarna Correspondence: a new edition of the cuneiform letters from the site of El-Amarna based on collations of all extant tablers. Leiden, Boston: Brill, 2015.

Submetido em: 16-5-2018

Aceito em: 24-5-2018 